\title{
A database for immunodeficiency due to mutations in nuclear factor kappa B pathway genes
}

\author{
Arnon Broides*
}

\begin{abstract}
Nuclear factor kappa B (NFKB) pathway defects are associated with immunodeficiency; however, multiple phenotypes for mutations in genes encoding for $\mathrm{NF} K \mathrm{~B}$ proteins have been reported. We sought to create a database of published mutations in the genes encoding for IKK $\alpha$ and IKK $\beta$ and the regulatory subunit IKK $\gamma$, also referred to as NFkB essential modulator (NEMO). All published mutations were reviewed. The clinical and laboratory phenotypes were recorded and yearly updates of new mutations and phenotypes will be performed. Multiple immunodeficiency and infectious phenotypes were recorded particularly for patients with NEMO gene mutations. Even patients with the same NEMO mutation tended to have somewhat different phenotypes. In patients with primary immunodeficiency, the clinical phenotype may not direct the clinician to the genetic cause of the disease. Therefore, a comprehensive database will expand our knowledge and enhance the clinician's ability to predict which gene mutation is the cause of the immunodeficiency. This database can assist clinicians in the diagnoses of patients with specific features of immunodeficiency.
\end{abstract}

Statement of novelty: A comprehensive database of published mutations in the genes encoding for IKK $\alpha$, $\mathrm{IKK} \beta$, and IKK $\gamma$ was created. This database may aid the clinician in recognizing specific immunodeficiency phenotypes.

\section{Introduction}

The nuclear factor kappa B (NFkB) family of transcription factors is essential for a variety of biological functions including response to stress, infection, and inflammation. The NFKB is normally found in the cytoplasm due to the effects of the inhibitor of NFKB, (IkB). Upon canonical stimulation of the NFKB pathway, the IкB components are phosphorylated by the I $\mathrm{B}$ kinase (IKK) which is composed of 2 catalytic subunits (IKK $\alpha$ and IKK $\beta$ ) and a regulatory subunit (IKK $\gamma$, also referred to as NEMO, NFKB essential modulator, IKBKG), leading to the degradation of the $I \kappa B$ which allows for translocation of the $\mathrm{NF \kappa B}$ into the nucleus and transcription of proinflammatory genes (Gilmore 2006).
As expected, mutations within this pathway have a deleterious effect on susceptibility to malignancies, development, and the immune system. Mutations in genes encoding for NEMO, I $\kappa K \alpha$, and IKK $\beta$ cause a wide variety of immunodeficiency phenotypes. The NEMO gene is found at the Xq28 region, males born with hypomorphic mutations in the NEMO gene usually suffer from combined immunodeficiency with or without ectodermal dysplasia. Null mutations in males are lethal in utero and female carriers of mutations in the NEMO gene have a typical skin condition with streaks of hyperpigmentation known as incontinenta pigmenti. Diseases from mutations in I KK $\alpha$ and IKK $\beta$ are inherited in an autosomal recessive manner (Courtois and Gilmore 2006). We have created a database (Tables 1-3) of published mutations in NEMO,
Pediatric Immunology Clinic, Soroka University Medical Center, Beer Sheva, Israel
Submitted 23 August 2016

Accepted 10 November 2016

Available online 14 November 2016

LymphoSign Journal 3:165-178 (2016)

dx.doi.org/10.14785/lymphosign-2016-0009 


\begin{tabular}{|c|c|c|c|c|c|c|}
\hline Nucleotide & Amino acid & Deficiency & Cellular immune function & $\begin{array}{l}\text { Serum immunoglobulin } \\
\text { levels }\end{array}$ & Presenting features & References \\
\hline $\begin{array}{l}\text { Splice site defect } \\
\text { at bp 4257, +1 } \\
\text { of exon1B } \\
\text { splice site }\end{array}$ & - & $\begin{array}{c}\text { T+B+ Antibody deficiency } \\
\text { Dysgammaglobulinemia }\end{array}$ & $\begin{array}{l}\text { Normal proliferation to PHA, } \\
\text { pokeweed mitogen, anti- } \\
\text { CD3; low proliferation to } \\
\text { tetanus; impaired cytokine } \\
\text { production after TLR } \\
\text { activation }\end{array}$ & $\begin{array}{l}\text { Normal or low IgM, normal } \\
\text { IgG and elevated IgA; } \\
\text { waning antibodies to } \\
\text { Streptococcus } \\
\text { Pneumoniae; no } \\
\text { response to Hepatitis B, } \\
\text { mumps, and measles } \\
\text { vaccines }\end{array}$ & $\begin{array}{l}\text { Otitis, adenitis, bronchitis/ } \\
\text { bronchopneumonia, } \\
\text { bronchiectasis, recurrent } \\
\text { diarrhea }\end{array}$ & $\begin{array}{l}\text { Mooster et al. } \\
2010\end{array}$ \\
\hline 110-111insC & $\Delta$ Nterm37 & $\begin{array}{l}\mathrm{T}+\mathrm{B}+\mathrm{NK}+\text { (with progressive } \\
\text { decline of T cells with age) } \\
\text { Combined immunodeficiency }\end{array}$ & $\begin{array}{l}\text { Normal to borderline } \\
\text { proliferation to PHA, } \\
\text { pokeweed mitogen; low } \\
\text { response to OKT3. Very low } \\
\text { IFN- } \gamma \text { production }\end{array}$ & $\begin{array}{l}\text { Elevated IgM, low IgG, } \\
\text { absent IgA, lgE; no } \\
\text { antibodies to tetanus } \\
\text { toxoid, Diptheria toxoid, } \\
\text { Pneumococcus, } \\
\text { Haemophilus } \\
\text { influenzae B }\end{array}$ & $\begin{array}{l}\text { Mycobacterium avium } \\
\text { lymphadenitis, } \\
\text { Bronchiestasis (Hemophilus } \\
\text { Influenzae and } \\
\text { Streptococcus pneumoniae } \\
\text { in sputum), Mycobacterium } \\
\text { Avium osteomyelitis, lethal } \\
\text { herpes encephalitis. } \\
\text { Salmonella enteritidis } \\
\text { bacteremia and enteritis, no } \\
\text { ectodermal dysplasia }\end{array}$ & $\begin{array}{l}\text { Niehues et al. } \\
\text { 2004; Puel } \\
\text { et al. 2006; } \\
\text { Hanson } \\
\text { et al. } 2008\end{array}$ \\
\hline $239 \mathrm{~T}>\mathrm{C}$ & $80 \mathrm{~L}>\mathrm{P}$ & $\begin{array}{l}\mathrm{T}+\mathrm{B}+\mathrm{NK}+\text { Combined } \\
\text { immunodeficiency }\end{array}$ & $\begin{array}{l}\text { Low proliferation to PHA poor } \\
\text { IL-6 production from } \\
\text { fibroblasts after TNF- } \alpha \text { and } \\
\text { IL1- } \beta \text { stimulation }\end{array}$ & $\begin{array}{l}\text { Low IgM, normal IgA and } \\
\text { IgG; no antibodies to } \\
\text { Pneumococcus }\end{array}$ & $\begin{array}{l}\text { Recurrent pneumococcal } \\
\text { infections, pneumonia, } \\
\text { episodes of orbital cellulitis } \\
\text { (Staphylococcus aureus } \\
\text { and candida), hypodontia, } \\
\text { conical incisor teeth, no } \\
\text { ectodermal dysplasia }\end{array}$ & $\begin{array}{l}\text { Ku et al. 2005; } \\
\text { Hanson et al. } \\
2008\end{array}$ \\
\hline $337 \mathrm{G}>\mathrm{A}$ & $113 \mathrm{D}>\mathrm{N}$ & $\begin{array}{l}\mathrm{T}+\mathrm{B}+\mathrm{NK}+\mathrm{Decreased} \mathrm{T-cell} \\
\text { function, low NK-cell activity }\end{array}$ & $\begin{array}{l}\text { Normal to slightly low } \\
\text { proliferation to PHA, ConA, } \\
\text { pokeweed mitogen; } \\
\text { TCR-induced NFkB } \\
\text { activation diminished; low } \\
\text { NK cytolytic activity }\end{array}$ & $\begin{array}{l}\text { Normal IgM and IgG, } \\
\text { absent IgA; normal } \\
\text { antibodies to Hemophilis } \\
\text { influenzae B, } \\
\text { Pneumococcus }\end{array}$ & $\begin{array}{l}\text { Pneumocystis jiroveci } \\
\text { pneumonia, CMV viremia, } \\
\text { no ectodermal dysplasia }\end{array}$ & $\begin{array}{l}\text { Hanson et al. } \\
\text { 2008; Salt } \\
\text { et al. } 2008\end{array}$ \\
\hline $\begin{array}{l}6 \mathrm{IVs} 6+5 \mathrm{G}>\mathrm{A} \\
(1027+5 \mathrm{G}>\mathrm{A})\end{array}$ & $\Delta 134-256$ & $\begin{array}{l}\mathrm{T}+\mathrm{B}+ \\
\text { Hypogammaglobulinemia }\end{array}$ & $\begin{array}{l}\text { Impaired IKB- } \alpha \text { degradation } \\
\text { after TNF- } \alpha \text { stimulation }\end{array}$ & $\begin{array}{l}\text { Hypogamamma- } \\
\text { globulinemia (or } \\
\text { hypergamma- } \\
\text { globulinemia); hyper IgA, } \\
\text { no antibodies to } \\
\text { Streptococcus } \\
\text { pneumoniae }\end{array}$ & $\begin{array}{l}\text { Ectodermal dysplasia, } \\
\text { inflammatory bowel } \\
\text { disease, pyogenic and } \\
\text { mycobacterial infections, } \\
\text { Small for gestational age, } \\
\text { failure to thrive, hypodontia, } \\
\text { conical incisor teeth, } \\
\text { immune dysregulation } \\
\text { (multiple patients with varied } \\
\text { phenotype) }\end{array}$ & $\begin{array}{l}\text { Orstavik et al. } \\
\text { 2006; Hanson } \\
\text { et al. } 2008\end{array}$ \\
\hline
\end{tabular}


Table 1: (Continued)

\begin{tabular}{|c|c|c|c|c|c|c|}
\hline Nucleotide & Amino acid & Deficiency & Cellular immune function & $\begin{array}{c}\text { Serum immunoglobulin } \\
\text { levels }\end{array}$ & Presenting features & References \\
\hline $437 \mathrm{~T}>\mathrm{G}$ & $146 V>G$ & $\begin{array}{l}\mathrm{T}+\mathrm{B}+\mathrm{NK}+ \\
\text { Hypogammaglobulinemia }\end{array}$ & - & $\begin{array}{l}\text { Absent } \lg G \text { and } \lg M, \\
\text { elevated } \lg A\end{array}$ & $\begin{array}{l}\text { Staphylococcus aureus } \\
\text { subdural empyema, } \\
\text { ectodermal dysplasia, } \\
\text { conical incisor tooth, failure } \\
\text { to thrive, eosinophilia }\end{array}$ & $\begin{array}{l}\text { Devora et al. } \\
2010\end{array}$ \\
\hline $458 \mathrm{~T}>\mathrm{G}$ & $153 \mathrm{~L}>\mathrm{R}$ & T+Hypogammaglobulinemia & $\begin{array}{l}\text { Normal proliferation to PHA, } \\
\text { pokeweed mitogen; } \\
\text { reduced proliferation to } \\
\text { ConA; reduced response to } \\
\text { tetanus and diphtheria; low } \\
\text { NK activity; normal antibody } \\
\text { directed cell cytotoxicity }\end{array}$ & $\begin{array}{l}\text { Hypogamma- } \\
\text { globulinemia; low lgM, } \\
\text { elevated lgA }\end{array}$ & $\begin{array}{l}\text { Ectodermal dysplasia, CMV } \\
\text { colitis, Listeria } \\
\text { monocytogenes sepsis, } \\
\text { Streptococcus bovis } \\
\text { meningitis }\end{array}$ & $\begin{array}{l}\text { Orange et al. } \\
\text { 2002, 2004a; } \\
\text { Brodeur } \\
\text { et al. 2003; } \\
\text { Deering and } \\
\text { Orange 2006; } \\
\text { Ku et al. 2007; } \\
\text { Hanson et al. } \\
\text { 2008; Salt et al. } \\
2008\end{array}$ \\
\hline $518 C>G$ & $173 R>G$ & $\begin{array}{l}\text { T+B+Antibody deficiency } \\
\text { (Dysgammaglobulinemia) }\end{array}$ & $\begin{array}{l}\text { Reduced IL-10 production } \\
\text { after TNF- } \alpha \text { stimulation; } \\
\text { slightly reduced IL-6 } \\
\text { production after LPS and } \\
\text { IL-1 } \beta \text { stimulation }\end{array}$ & $\begin{array}{l}\text { Normal immunoglobulins; } \\
\text { specific antibody defects } \\
\text { (Streptococcus } \\
\text { pneumoniae, tetanus, } \\
\text { Hemophilis influenza B, } \\
\text { pertussis toxoid) }\end{array}$ & $\begin{array}{l}\text { Ectodermal dysplasia, } \\
\text { Immune dysregulation, } \\
\text { Streptococcus pneumoniae } \\
\text { cellulitis }\end{array}$ & $\begin{array}{l}\text { Ku et al. 2007; } \\
\text { Hanson et al. } \\
2008\end{array}$ \\
\hline $524 \mathrm{G}>\mathrm{C}$ & $175 R>P$ & T+B+Dysgammaglobulinemia & Normal responses & $\begin{array}{l}\text { Normal IgM, low lgG2, } \\
\text { elevated IgG4, IgA; } \\
\text { specific antibody defects } \\
\text { (Streptococcus } \\
\text { pneumoniae) }\end{array}$ & $\begin{array}{l}\text { Ectodermal dysplasia, } \\
\text { Immune dysregulation, } \\
\text { Streptococcus pneumoniae } \\
\text { meningitis }\end{array}$ & $\begin{array}{l}\text { Abinun et al. } \\
\text { 1996; } \\
\text { Doffinger et al. } \\
\text { 2001; Carrol } \\
\text { et al. 2003; } \\
\text { Hanson } \\
\text { et al. } 2008\end{array}$ \\
\hline Non-specified & $217 \mathrm{R}>\mathrm{G}$ & $\begin{array}{l}\text { T+B+Dysgamma- } \\
\text { globulinemia }\end{array}$ & - & $\begin{array}{l}\text { Normal to elevated lgG, } \\
\lg M, \lg A\end{array}$ & $\begin{array}{l}\text { Ectodermal dysplasia, } \\
\text { recurrent pneumonia, } \\
\text { recurrent otitis/sinusitis }\end{array}$ & $\begin{array}{l}\text { Lee et al. 2005; } \\
\text { Hanson et al. } \\
2008\end{array}$ \\
\hline Exon 4-5 dup & $\mathrm{K} 224 \mathrm{fs} \times 9$ & $\begin{array}{l}\text { T+ (low CD4)Combined } \\
\text { immunodeficiency }\end{array}$ & $\begin{array}{l}\text { Low proliferation to PHA, } \\
\text { ConA; normal response to } \\
\text { PMA-ionomycin; low } \\
\text { response to LPS stimulation }\end{array}$ & $\begin{array}{l}\text { Low PHA, ConA; normal } \\
\text { PMA-ionomycin; low } \\
\text { response to LPS } \\
\text { stimulation }\end{array}$ & $\begin{array}{l}\text { Ectodermal dysplasia, } \\
\text { transient lymphedema, } \\
\text { diarrhea, delayed teeth, } \\
\text { pneumonia, } \\
\text { Staphylococcus aureus } \\
\text { cellulitis, Pseudomonas } \\
\text { aeruginosa sinusitis/otitis, } \\
\text { diarrhea }\end{array}$ & $\begin{array}{l}\text { Nishikomori } \\
\text { et al. 2004; } \\
\text { Hanson } \\
\text { et al. } 2008\end{array}$ \\
\hline 667_669del & $\Delta \mathrm{E} 223$ & $\begin{array}{l}\mathrm{T}+\mathrm{B}+\mathrm{NK}+ \\
\text { Dysgammaglobulinemia }\end{array}$ & $\begin{array}{l}\text { Normal responses to } \\
\text { mitogens and antigens; low } \\
\text { NK activity; Impaired TLR } \\
\text { signaling to agonists }\end{array}$ & $\begin{array}{l}\text { Normal IgG, low IgM and } \\
\text { elevated IgG; Partial } \\
\text { antibodies to } \\
\text { Streptococcus } \\
\text { pneumoniae, low tetanus } \\
\text { and diptheria antibodies }\end{array}$ & $\begin{array}{l}\text { Ectodermal dysplasia, } \\
\text { recurrent sinopulmonary } \\
\text { infections, } 2 \text { pneumonias }\end{array}$ & $\begin{array}{l}\text { Karamchandani- } \\
\text { Patel et al. } \\
2011\end{array}$ \\
\hline
\end{tabular}


Table 1: (Continued)

\begin{tabular}{lccc} 
Nucleotide & Amino acid & Deficiency & Cellular immune function \\
\hline $667 \mathrm{G}>\mathrm{A}$ & $223 \mathrm{E}>\mathrm{K}$ & $\mathrm{T}+\mathrm{B}+\mathrm{NK}+$ \\
& & Dysgammaglobulinemia & Low NK activity; impaired \\
& & TLR signaling to agonists
\end{tabular}

Serum immunoglobulin

levels

Low IgM, normal IgG and

$\lg A$; tetanus toxoid and

diptheria antibodies low

to normal

\begin{tabular}{|c|c|c|c|c|}
\hline $680 \mathrm{~T}>\mathrm{C}$ & $227 \mathrm{~L}>\mathrm{P}$ & Hypogammaglobulinemia & Low NK activity & $\begin{array}{l}\text { Normal to low } \\
\text { immunoglobulins; no } \\
\text { antibodies to } \\
\text { Streptococcus } \\
\text { pneumoniae }\end{array}$ \\
\hline
\end{tabular}

$\begin{array}{ccc}769-1 G>C \quad I V S 6 & \begin{array}{c}\text { T+B+NK+ (low B cells) } \\ \text { Dysgammaglobulinemia }\end{array} & \begin{array}{l}\text { Low NK activity; impaired } \\ \text { TNF- } \alpha \text { production after LPS } \\ \text { stimulation }\end{array}\end{array}$

Normal immunoglobulins,

impaired antibody

production to measles

and Streptococcus

pneumoniae, normal

antibodies to CMV/EBV,

measles, varicella

$760 \mathrm{C}>\mathrm{G}$

$254 \mathrm{R}>\mathrm{G}$

$T+$ (low CD4) $T$ cell deficiency

Normal delayed type

hypersensitivity and

antibody directed cell

cytotoxicity, low NK activity

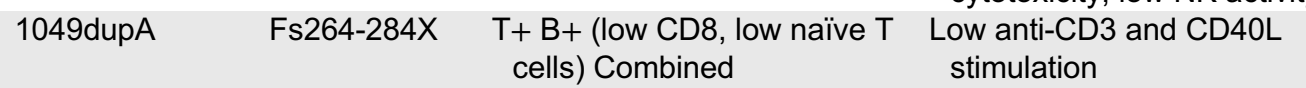

Normal to elevated

immunoglobulins

immunodeficiency

Elevated lgM, low lgG, normal $\lg \mathrm{A}$

Presentures

References

Karamchandani-

Patel et al.

necrotizing MRSA soft

2011

abscess, Streptococcus

anginosus bacteremia,

conical teeth

Ectodermal dysplasia,

inflammatory bowel

disease, immune

dysregulation, pyogenic

infections (multiple patients

with varied phenotype)

Recurrent Streptococcus

pneumoniae meningitis,

septic arthritis, cellulitis,

measles, osteomyelitis,

hypodontia, conical teeth

Schweizer et al.

1999; Doffinger

et al. 2001; von

Bernuth et al.

2005; Hanson

et al. 2008

Karakawa et al.

2011

\section{Mycobacterium avium}

intracellulare infections of

Haverkamp

et al. 2004;

skin, muscle and lungs

Hanson

et al. 2008

Incontinentia pigmenti,

Martinez-Poma

pneumonia (RSV,

et al. 2005;

Streptococcus pneumoniae, Hanson et al.

Candida albicans sepsis/

2008

bacteremia, Aspergillus

fumigates osteomyelitis,

EBV infection

\begin{tabular}{|c|c|c|c|}
\hline 811_828del & $\Delta 271-276$ & $\begin{array}{l}\mathrm{T}+\mathrm{B}+\mathrm{NK}+ \\
\text { Dysgammaglobulinemia }\end{array}$ & $\begin{array}{l}\text { Normal proliferation to PHA } \\
\text { and PMA/ionomycin; } \\
\text { reduced TNF- } \alpha \text { and IL-1 } \\
\text { stimulation }\end{array}$ \\
\hline $863 C>G$ & $288 A>G$ & Combined immunodeficiency & $\begin{array}{l}\text { Normal PHA, normal PMA/l; } \\
\text { reduced TNF- } \alpha \text { and LPS } \\
\text { stimulation, reduced NFאB } \\
\text { activation }\end{array}$ \\
\hline $931 \mathrm{G}>\mathrm{A}$ & $311 \mathrm{D}>\mathrm{N}$ & - & $\begin{array}{l}\text { Impaired IL12p40 production } \\
\text { from EBV transformed B } \\
\text { cells after PMA stimulation }\end{array}$ \\
\hline
\end{tabular}

Elevated IgA, normal IgG and IgM; no antibodies to

Pneumococcus

Recurrent pneumococcal

Ku et al. 2005

infections, pneumonia,

hypodontia, conical incisor teeth

Ectodermal dysplasia,

immune dysregulation,

Streptococcus pneumoniae

infection

Doffinger et al. 2001; Vinolo

et al. 2006

Hanson

et al. 2008

Ectodermal dysplasia, Doffinger et al. immune dysregulation, 2001; Hanson Streptococcus pneumoniae et al. 2008 infection, Mycobacterium avium infections 
Table 1: (Continued)

\begin{tabular}{|c|c|c|c|c|c|c|}
\hline Nucleotide & Amino acid & Deficiency & Cellular immune function & $\begin{array}{l}\text { Serum immunoglobulin } \\
\text { levels }\end{array}$ & Presenting features & References \\
\hline $932 A>G$ & $311 \mathrm{D}>\mathrm{G}$ & $\mathrm{T}+\mathrm{B}+$ & $\begin{array}{l}\text { Normal T-cell proliferation to } \\
\text { PHA and antigens; reduced } \\
\text { NFkB activity, IkB- } \alpha \\
\text { degradation, impaired IL-6 } \\
\text { and IL-8 production from } \\
\text { fibroblasts after TNF- } \alpha \text { and } \\
\text { IL-1 } \beta \text { stimulation; impaired } \\
\text { IL12p40 production from } \\
\text { EBV transformed B cells } \\
\text { after PMA stimulation }\end{array}$ & $\begin{array}{l}\text { Normal IgM and IgG, } \\
\text { elevated IgA; normal } \\
\text { anti-A antibody, low anti- } \\
\text { B antibody }\end{array}$ & $\begin{array}{l}\text { Streptococcus pneumoniae } \\
\text { pneumonia and otitis. } \\
\text { Mycobacterium avium } \\
\text { adenitis and later } \\
\text { Mycobacterium abscessus, } \\
\text { absent adult maxillary } \\
\text { lateral incisors and right } \\
\text { premolar }\end{array}$ & $\begin{array}{l}\text { Hubeau et al. } \\
2011\end{array}$ \\
\hline $932 A>G$ & 311D >E & $\mathrm{T}+\mathrm{B}+\mathrm{NK}+$ & $\begin{array}{l}\text { Normal proliferation to PHA, } \\
\text { ConA; slightly reduced NK } \\
\text { activity; impaired PBMC } \\
\text { release of IFN- } \gamma \text { after IL-12 } \\
\text { stimulation and TNF- } \alpha \text { after } \\
\text { LPS stimulation }\end{array}$ & $\begin{array}{l}\text { Low IgM, normal lgG, } \\
\text { elevated IgA; no } \\
\text { antibodies to measles, } \\
\text { positive for rubella. }\end{array}$ & $\begin{array}{l}\text { Disseminated Bacillus } \\
\text { Calmette-Guérin, } \\
\text { generalized } \\
\text { lymphadenopathy, parotitis, } \\
\text { Streptococcus pneumoniae } \\
\text { sepsis }\end{array}$ & $\begin{array}{l}\text { Imamura et al. } \\
2011\end{array}$ \\
\hline $944 \mathrm{~A}>\mathrm{C}$ & $315 E>A$ & $\mathrm{~T}+\mathrm{B}+$ & $\begin{array}{l}\text { Normal proliferation to PHA; } \\
\text { reduced interferon } \gamma \\
\text { production in response to } \\
\text { PMA/ionomycin; normal } \\
\text { response to LPS }\end{array}$ & $\begin{array}{l}\text { Normal immunoglobulins } \\
\text { or elevated IgG }\end{array}$ & $\begin{array}{l}\text { Ectodermal dysplasia, } \\
\text { Mycobacteria avium } \\
\text { intracellulare infections, } \\
\text { diarrhea, hypodontia, } \\
\text { conical incisor teeth, failure } \\
\text { to thrive (multiple patients } \\
\text { with varied phenotype) }\end{array}$ & $\begin{array}{l}\text { Holland et al. } \\
\text { 1994; } \\
\text { Haverkamp } \\
\text { et al. 2004; } \\
\text { Filipe-Santos } \\
\text { et al. 2006; von } \\
\text { Bernuth et al. } \\
\text { 2006; Hanson } \\
\text { et al. } 2008\end{array}$ \\
\hline $956 \mathrm{G}>\mathrm{A}$ & $319 R>Q$ & $\mathrm{~T}+\mathrm{B}+$ & $\begin{array}{l}\text { Reduced response to CD40L } \\
\text { stimulation; normal TLR and } \\
\text { IL-1 stimulation; normal to } \\
\text { reduced response to TNF- } \alpha \\
\text { stimulation }\end{array}$ & $\begin{array}{l}\text { Normal to elevated lgG, } \\
\text { IgM; normal IgA }\end{array}$ & $\begin{array}{l}\text { Mycobacteria avium } \\
\text { intracellulare cellulitis/ } \\
\text { abscess, Haemophilus } \\
\text { influenzae cellulitis/ } \\
\text { abscess, diarrhea, } \\
\text { Pulmonary tuberculosis }\end{array}$ & $\begin{array}{l}\text { Filipe-Santos } \\
\text { et al. 2006; von } \\
\text { Bernuth et al. } \\
\text { 2006; Hanson } \\
\text { et al. } 2008\end{array}$ \\
\hline 991del9 & E3331del3 & $\mathrm{T}+($ low CD4)T-cell deficiency & - & $\begin{array}{l}\text { Elevated IgG; IgM not } \\
\text { elevated }\end{array}$ & $\begin{array}{l}\text { Recurrent Streptococcus } \\
\text { pneumoniae infections, } \\
\text { warts, Mycobacteria avium } \\
\text { intracellulare infections }\end{array}$ & $\begin{array}{l}\text { Haverkamp } \\
\text { et al. 2004; } \\
\text { Hanson } \\
\text { et al. } 2008\end{array}$ \\
\hline $1056 \mathrm{G}>\mathrm{A}$ & $\Delta 353-373$ & $\begin{array}{l}\text { T+B+ } \\
\text { Dysgammaglobulinemia }\end{array}$ & $\begin{array}{l}\text { Reduced NK activity; reduced } \\
\text { response to IL-1 and TLR } \\
\text { stimulation }\end{array}$ & $\begin{array}{l}\text { Normal IgG and IgM, } \\
\text { elevated IgA; no } \\
\text { antibodies to tetanus } \\
\text { toxoid, Haemophilus } \\
\text { influenzae B }\end{array}$ & $\begin{array}{l}\text { Recurrent pneumonia, } \\
\text { Haemophilis influenzae } \\
\text { bacteremia/sepsis, } \\
\text { Mycobacterium bovis } \\
\text { infections }\end{array}$ & $\begin{array}{l}\text { Dai et al. 2004; } \\
\text { Orange et al. } \\
\text { 2004a, 2004b; } \\
\text { Hanson et al. } \\
2008 \\
\quad \text { (continued) }\end{array}$ \\
\hline
\end{tabular}


Table 1: (Continued)

\begin{tabular}{|c|c|c|c|c|c|c|}
\hline Nucleotide & Amino acid & Deficiency & Cellular immune function & $\begin{array}{c}\text { Serum immunoglobulin } \\
\text { levels }\end{array}$ & Presenting features & References \\
\hline 1161insC & P389fsX4 & Hypogammaglobulinemia & Reduced NFкB activation & Low $\lg G$, elevated $\lg E$ & $\begin{array}{l}\text { Ectodermal dysplasia, } \\
\text { hypodontia, conical incisor } \\
\text { teeth, abdominal pain, } \\
\text { failure to thrive, pneumonia, } \\
\text { bronchiectasis, cellulitis, } \\
\text { Mycobacteria avium } \\
\text { intracellulare infections }\end{array}$ & $\begin{array}{l}\text { Aradhya et al. } \\
\text { 2001; Kosaki } \\
\text { et al. 2001; } \\
\text { Hanson } \\
\text { et al. } 2008\end{array}$ \\
\hline 1167insC & E390fsX5 & $\mathrm{T}+\mathrm{B}+\mathrm{T}$-cell deficiency & $\begin{array}{l}\text { Normal proliferation to } \\
\text { mitogens; no proliferation to } \\
\text { anti-CD3, tetanus toxoid, } \\
\text { diphtheria; low NK activity; } \\
\text { reduced response to LPS }\end{array}$ & $\begin{array}{l}\text { Elevated to low IgM, } \\
\text { normal or low IgG, low } \\
\lg A\end{array}$ & $\begin{array}{l}\text { Ectodermal dysplasia, } \\
\text { osteopetrosis, hypodontia, } \\
\text { conical incisor teeth, } \\
\text { immune dysregulation, } \\
\text { failure to thrive, diarrhea, } \\
\text { Pneumocystis jiroveci } \\
\text { pneumonia, } \\
\text { Staphylococcus aureus, } \\
\text { streptococcus pneumoniae } \\
\text { infections, Mycobacterial } \\
\text { avium intracellulare } \\
\text { infections, CMV infection }\end{array}$ & $\begin{array}{l}\text { Hanson et al. } \\
\text { 2008; Mancini } \\
\text { et al. } 2008\end{array}$ \\
\hline $1171 \mathrm{G}>\mathrm{T}$ & $391 \mathrm{E}>\mathrm{X}$ & $\begin{array}{l}\text { T+B+ } \\
\text { Dysgammaglobulinemia }\end{array}$ & $\begin{array}{l}\text { Normal proliferation to } \\
\text { mitogens }\end{array}$ & $\begin{array}{l}\text { Normal IgM, elevated IgG } \\
\text { IgA; no antibodies to } \\
\text { Streptococcus } \\
\text { pneumoniae }\end{array}$ & $\begin{array}{l}\text { Ectodermal dysplasia, conical } \\
\text { teeth, inflammatory bowel } \\
\text { disease, immune } \\
\text { dysregulation, recurrent } \\
\text { pneumonia, cellulitis, } \\
\text { Streptococcus Pneumoniae } \\
\text { infections (meningitis, } \\
\text { pneumonia), giardiasis } \\
\text { (multiple patients with varied } \\
\text { phenotype) }\end{array}$ & $\begin{array}{l}\text { Zonana et al. } \\
\text { 2000; Hanson } \\
\text { et al. } 2008\end{array}$ \\
\hline 1426insC & S387fsX8 & $\begin{array}{l}\text { T+B+Hypogamma- } \\
\text { globulinemia }\end{array}$ & $\begin{array}{l}\text { Normal proliferation to } \\
\text { mitogens and to tetanus, } \\
\text { candida, diphtheria }\end{array}$ & Normal IgM, low IgG IgM & $\begin{array}{l}\text { Ectodermal dysplasia, } \\
\text { diarrhea, failure to thrive, } \\
\text { meningitis/encephalitis, } \\
\text { recurrent pneumonia and } \\
\text { sinusitis, diarrhea, } \\
\text { Molluscum contagiosum } \\
\text { virus }\end{array}$ & $\begin{array}{l}\text { Lee et al. 2005; } \\
\text { Hanson et al. } \\
2008\end{array}$ \\
\hline
\end{tabular}




\begin{tabular}{|c|c|c|c|c|c|c|}
\hline Nucleotide & Amino acid & Deficiency & Cellular immune function & $\begin{array}{l}\text { Serum immunoglobulin } \\
\text { levels }\end{array}$ & Presenting features & References \\
\hline 1182_1183delTT & $420 X>W$ & Hypogammaglobulinemia & - & $\begin{array}{l}\text { Elevated IgM, low lgG, } \\
\text { normal } \lg A\end{array}$ & $\begin{array}{l}\text { Ectodermal dysplasia, } \\
\text { osteopetrosis, } \\
\text { lymphedema, Enterobacter } \\
\text { cloacae sepsis, pustulosis, } \\
\text { Group A strepococcus } \\
\text { septic arthritis, Salmonella } \\
\text { and adenovirus } \\
\text { gastroenteritis, multiple skin } \\
\text { abscesses, Molluscum } \\
\text { contagiousum, otitis media } \\
\text { (multiple patients) }\end{array}$ & $\begin{array}{l}\text { Roberts et al. } \\
2010\end{array}$ \\
\hline $1207 \mathrm{C}>\mathrm{T}$ & $403 Q>X$ & $\begin{array}{l}\mathrm{T}+\mathrm{B}+\text { (low CD4 later in life) } \\
\text { Combined immunodeficiency }\end{array}$ & $\begin{array}{l}\text { Normal proliferation to PHA, } \\
\text { pokeweed mitogen, low } \\
\text { ConA; reduced proliferation } \\
\text { to antigens; low NK activity, } \\
\text { normal ADCC, reduced } \\
\text { response to CD40L } \\
\text { stimulation }\end{array}$ & $\begin{array}{l}\text { Low IgM and lgG, elevated } \\
\lg A\end{array}$ & $\begin{array}{l}\text { Ectodermal dysplasia, } \\
\text { immune dysregulation, } \\
\text { Streptococcus pneumoniae, } \\
\text { Pseudomonas aeruginosa } \\
\text { meningitis/encephalitis and } \\
\text { osteomyelitis. Herpes } \\
\text { simplex virus oral infection, } \\
\text { Pneumonia, Mycobacterium } \\
\text { avium intracellulare } \\
\text { infection of blood, bone } \\
\text { marrow and skin }\end{array}$ & $\begin{array}{l}\text { Orange et al. } \\
\text { 2002, 2004a; } \\
\text { Dai et al. 2004; } \\
\text { Hanson } \\
\text { et al. } 2008\end{array}$ \\
\hline $1217 \mathrm{~A}>\mathrm{T}$ & $406 \mathrm{D}>\mathrm{V}$ & $\begin{array}{l}\mathrm{T}+\mathrm{B}+\text { Combined } \\
\text { immunodeficiency }\end{array}$ & $\begin{array}{l}\text { Low proliferation to CD3; } \\
\text { normal response to TNF- } \alpha \\
\text { and LPS stimulation; } \\
\text { reduced CD40L stimulation, } \\
\text { reduced IFN- } \gamma \text { production }\end{array}$ & $\begin{array}{l}\text { Normal IgM, low lgG and } \\
\lg A\end{array}$ & $\begin{array}{l}\text { Ectodermal dysplasia, } \\
\text { Streptococcus pneumoniae } \\
\text { infections, sinusitis/otitis }\end{array}$ & $\begin{array}{l}\text { Jain et al. 2001; } \\
\text { Hanson et al. } \\
2008\end{array}$ \\
\hline 1218insA & D406fsX12 & $\begin{array}{l}\text { T+B+Combined } \\
\text { immunodeficiency }\end{array}$ & - & - & $\begin{array}{l}\text { Ectodermal dysplasia, } \\
\text { immune dysregulation, } \\
\text { Streptococcus pneumoniae } \\
\text { infections }\end{array}$ & $\begin{array}{l}\text { Doffinger et al. } \\
\text { 2001; Hanson } \\
\text { et al. } 2008\end{array}$ \\
\hline \multirow[t]{2}{*}{ 1235insC } & $1412 \mathrm{fs} \times 6$ & - & - & $\begin{array}{l}\text { Low } \lg G, \lg M \text { and } \lg A ; \text { no } \\
\text { tetanus antibodies }\end{array}$ & $\begin{array}{l}\text { Ectodermal dysplasia, } \\
\text { Mycobacterium avium } \\
\text { intracellulare infection }\end{array}$ & $\begin{array}{l}\text { Orange et al. } \\
\text { 2005; Hanson } \\
\text { et al. } 2008\end{array}$ \\
\hline & & & & & & (continued) \\
\hline
\end{tabular}




\begin{tabular}{|c|c|c|c|c|c|c|}
\hline Nucleotide & Amino acid & Deficiency & Cellular immune function & $\begin{array}{c}\text { Serum immunoglobulin } \\
\text { levels }\end{array}$ & Presenting features & References \\
\hline 1249T $>C$ & $417 C>R$ & $\begin{array}{l}\text { T+B+Dysgamma- } \\
\text { globulinemia }\end{array}$ & $\begin{array}{l}\text { Normal proliferation to PHA, } \\
\text { normal anti-CD3; no } \\
\text { proliferation to tetanus } \\
\text { toxoid and diphtheria; low } \\
\text { NK activity; reduced DTH } \\
\text { and IFN- } \gamma \text { production; } \\
\text { normal antibody directed } \\
\text { cell cytotoxicity }\end{array}$ & $\begin{array}{l}\text { Normal or elevated lgM, } \\
\text { low lgG, low or elevated } \\
\operatorname{lgA} \text {; no tetanus } \\
\text { antibodies after } \\
\text { immunization }\end{array}$ & $\begin{array}{l}\text { Ectodermal dysplasia, } \\
\text { hypodontia, conical incisor } \\
\text { teeth, immune } \\
\text { dysregulation, pneumonia, } \\
\text { bronchiectasis, } \\
\text { osteomyelitis, cellulitis/ } \\
\text { abscess, sinusitis/otitis, } \\
\text { Molluscum contagiosum, } \\
\text { Staphylococcus aureus } \\
\text { adenitis, Klebsiella } \\
\text { pneumonia bacteremia/ } \\
\text { sepsis, Mycobacterium } \\
\text { abscessus osteomyelitis } \\
\text { (multiple patients with varied } \\
\text { phenotype) }\end{array}$ & $\begin{array}{l}\text { Zonana et al. } \\
\text { 2000; } \\
\text { Doffinger et al. } \\
\text { 2001; Jain } \\
\text { et al. 2001; } \\
\text { Hanson et al. } \\
2008\end{array}$ \\
\hline $1250 G>T$ & $417 \mathrm{C}>\mathrm{F}$ & Hypogamma-globulinemia & - & $\begin{array}{l}\text { Elevated IgM and IgA, low } \\
\text { IgG; no antibodies to } \\
\text { Streptococcus } \\
\text { pneumoniae after } \\
\text { immunization }\end{array}$ & $\begin{array}{l}\text { Ectodermal dysplasia, conical } \\
\text { incisors, hypodontia, } \\
\text { immune dysregulation, } \\
\text { Streptococcus pneumoniae } \\
\text { infections, recurrent viral } \\
\text { and Streptococcus } \\
\text { Pneumoniae meningitis, } \\
\text { bronchiectasis }\end{array}$ & $\begin{array}{l}\text { Zonana et al. } \\
\text { 2000; } \\
\text { Doffinger et al. } \\
\text { 2001; Hanson } \\
\text { et al. } 2008\end{array}$ \\
\hline $1250 \mathrm{G}>\mathrm{A}$ & $417 \mathrm{C}>\mathrm{Y}$ & Hypogamma-globulinemia & $\begin{array}{l}\text { Normal proliferation to } \\
\text { mitogens and tetanus } \\
\text { toxoid; low NK activity; } \\
\text { normal DTH; low NFKB } \\
\text { activation and CD4OL } \\
\text { stimulation }\end{array}$ & $\begin{array}{l}\text { Normal lgM, low } \lg G \text { and } \\
\lg A\end{array}$ & $\begin{array}{l}\text { Ectodermal dysplasia, conical } \\
\text { incisors, Streptococcus } \\
\text { pneumoniae meningitis } \\
\text { (multiple patients with varied } \\
\text { phenotype) }\end{array}$ & $\begin{array}{l}\text { Brodeur et al. } \\
\text { 2003; Orange } \\
\text { et al. 2004a; } \\
\text { Hanson } \\
\text { et al. } 2008\end{array}$ \\
\hline $1259 A>G$ & X420WroX447 & $\begin{array}{l}\text { T+B+Hypogamma- } \\
\text { globulinemia }\end{array}$ & $\begin{array}{l}\text { Normal proliferation to } \\
\text { antigens; low IFN- } \gamma \\
\text { production; low response to } \\
\text { TNF- } \alpha, \text { IL-1, LPS, CD40L } \\
\text { stimulation and NFKB } \\
\text { activation }\end{array}$ & $\begin{array}{l}\text { Low } \operatorname{lgM}, \lg G \text { and } \lg \mathrm{A} \text { or } \\
\text { normal IgM and IgA with } \\
\text { low IgG; low } \\
\text { Streptococcus } \\
\text { pneumoniae antibodies } \\
\text { after immunization }\end{array}$ & $\begin{array}{l}\text { Ectodermal dysplasia, } \\
\text { osteopetrosis, } \\
\text { lymphedema, immune } \\
\text { dysregulation, delayed } \\
\text { eruption of teeth, } \\
\text { vancomycin resistant } \\
\text { enterococci, } \\
\text { Staphylococcus aureus } \\
\text { cellulitis/abscess, atypical } \\
\text { mycobacteria osteomyelitis, } \\
\text { adenovirus infection, oral } \\
\text { herpes simplex virus } \\
\text { (multiple patients with varied } \\
\text { phenotype) }\end{array}$ & $\begin{array}{l}\text { Doffinger et al. } \\
\text { 2001; Mansour } \\
\text { et al. 2001; } \\
\text { Dupuis-Girod } \\
\text { et al. 2002; von } \\
\text { Bernuth et al. } \\
\text { 2005; Hanson } \\
\text { et al. 2008 }\end{array}$ \\
\hline
\end{tabular}


Table 2: ІкB kinase $\alpha$ (IKK $\alpha)$.

\begin{tabular}{|c|c|c|c|c|c|c|}
\hline Nucleotide & $\begin{array}{l}\text { Amino } \\
\text { acid }\end{array}$ & Deficiency & Cellular immune function & Serum immunoglobulin levels & Presenting features & References \\
\hline $25 \mathrm{C}>\mathrm{T}$ & $9 Q>X$ & $\mathrm{~T}+\mathrm{B}+$ & $\begin{array}{l}\text { Low to normal proliferation to PHA ConA; } \\
\text { reduced TNF- } \alpha \text { production after LPS } \\
\text { stimulation in CD14 positive cells }\end{array}$ & High $\lg A$, normal $\lg M$ and $\lg G$ & $\begin{array}{l}\text { Ectodermal dysplasia, } \\
\text { Cytomegalovirus, Rotavirus, } \\
\text { pneumonia, otitis media }\end{array}$ & $\begin{array}{l}\text { Ohnishi et al. } \\
2012\end{array}$ \\
\hline $110 \mathrm{~T}>\mathrm{A}$ & $37 \mathrm{M}>\mathrm{K}$ & $\begin{array}{l}\text { T+B+ } \\
\text { Hypogamma- } \\
\text { globulinemia }\end{array}$ & $\begin{array}{l}\text { Normal proliferation to PHA, ConA, } \\
\text { pokeweed mitogen and antigens; } \\
\text { reduced proliferation to CD3; reduced } \\
\text { IL-6 production in whole blood after IL-1 } \beta \text {, } \\
\text { TLR2/6 agonist; reduced responses to } \\
\text { LPS and PMA/lonomycin; absent IL-10 } \\
\text { production following TNF- } \alpha \text { stimulation }\end{array}$ & $\begin{array}{l}\text { High IgM, absent lgG and IgA; } \\
\text { no specific antibodies to } \\
\text { diphtheria, tetanus, } \\
\text { Haemophilus influenzae B, } \\
\text { Streptococcus pneumoniae }\end{array}$ & $\begin{array}{l}\text { Hyper IgM syndrome/SCID; } \\
\text { polyendocrinpathy (autoimmune } \\
\text { thyroiditis, hypothalamic } \\
\text { hypopituitarism), ectodermal } \\
\text { dysplasia, chronic } \\
\text { mucoccutaneous candidiasis, } \\
\text { chronic diarrhea, failure to thrive }\end{array}$ & $\begin{array}{l}\text { Schimke et al. } \\
2013\end{array}$ \\
\hline $40 G>T$ & $14 \mathrm{E}>\mathrm{X}$ & $\mathrm{T}+\mathrm{B}+\mathrm{NK}-$ & $\begin{array}{l}\text { Normal proliferation to PHA, ConA, } \\
\text { pokeweed mitogen; low IFN- } \gamma \text { production } \\
\text { after anti-CD3 stimulation (restored by } \\
\text { addition of IL-12) }\end{array}$ & Normal immunoglobulins & $\begin{array}{l}\text { Pneumocystis jiroveci pneumonia, } \\
\text { oral candidiasis, failure to thrive, } \\
\text { recurrent pyogenic bacterial } \\
\text { infections, anhidrosis }\end{array}$ & $\begin{array}{l}\text { Lopez- } \\
\text { Granados } \\
\text { et al. } 2008\end{array}$ \\
\hline $32 G>A$ & $11 W>X$ & $\mathrm{~T}+\mathrm{B}+\mathrm{NK}+$ & $\begin{array}{l}\text { Normal proliferation to PHA, anti-CD3, } \\
\text { anti-CD3+anti-CD28, PMA, tetanus and } \\
\text { diphtheria; reduced TNF- } \alpha \text { production after } \\
\text { stimulation with TLR3, TLR4, TLR5, TLR9 } \\
\text { agonists; normal TNF- } \alpha \text { production after } \\
\text { TLR7 agonist; reduced IFN- } \alpha \text { production } \\
\text { after TLR3 and TLR9 agonists }\end{array}$ & $\begin{array}{l}\text { Normal immunoglobulins; } \\
\text { normal antibodies to tetanus } \\
\text { toxoid; no specific antibodies } \\
\text { to Pneumococcus }\end{array}$ & $\begin{array}{l}\text { Recurrent pneumonia with } \\
\text { bronchiectasis, no episodes of } \\
\text { bacteremia }\end{array}$ & $\begin{array}{l}\text { McDonald } \\
\text { et al. } 2007\end{array}$ \\
\hline $94 \mathrm{G}>\mathrm{T}$ & $32 S>1$ & $\begin{array}{l}\mathrm{T}+\mathrm{B}+\mathrm{NK}+ \\
\text { Combined } \\
\text { immunodeficiency }\end{array}$ & $\begin{array}{l}\text { Low to normal proliferation to PHA; low } \\
\text { proliferation to anti-CD3, OKT3; normal } \\
\text { proliferation to PHA+IL-2, OKT3+IL-2; no } \\
\text { proliferation to tetanus toxoid and candida; } \\
\text { reduced IL12p40 production in monocytes } \\
\text { after LPS stimulation; reduced IL-6 } \\
\text { production from whole blood after LPS } \\
\text { stimulation; normal } \\
\text { TNF- } \alpha \text { and IL-1 } \beta \text { production after LPS } \\
\text { stimulation; normal NK activity }\end{array}$ & $\begin{array}{l}\text { High IgM, absent IgG and } \lg A ; \\
\text { no specific antibodies after } \\
\text { immunizations }\end{array}$ & $\begin{array}{l}\text { Pneumocystis jiroveci pneumonia, } \\
\text { Streptococcus A meningitis, } \\
\text { neurodevelopmental regression, } \\
\text { ectodermal dysplasia, periodic } \\
\text { diarrhea, candidiasis, failure to } \\
\text { thrive, bronchopneumonitis, } \\
\text { hepatosplenomegaly }\end{array}$ & $\begin{array}{l}\text { Courtois et al. } \\
\text { 2003; } \\
\text { Janssen et al. } \\
2004\end{array}$ \\
\hline
\end{tabular}




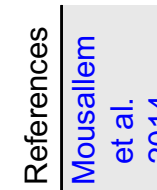

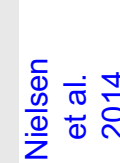
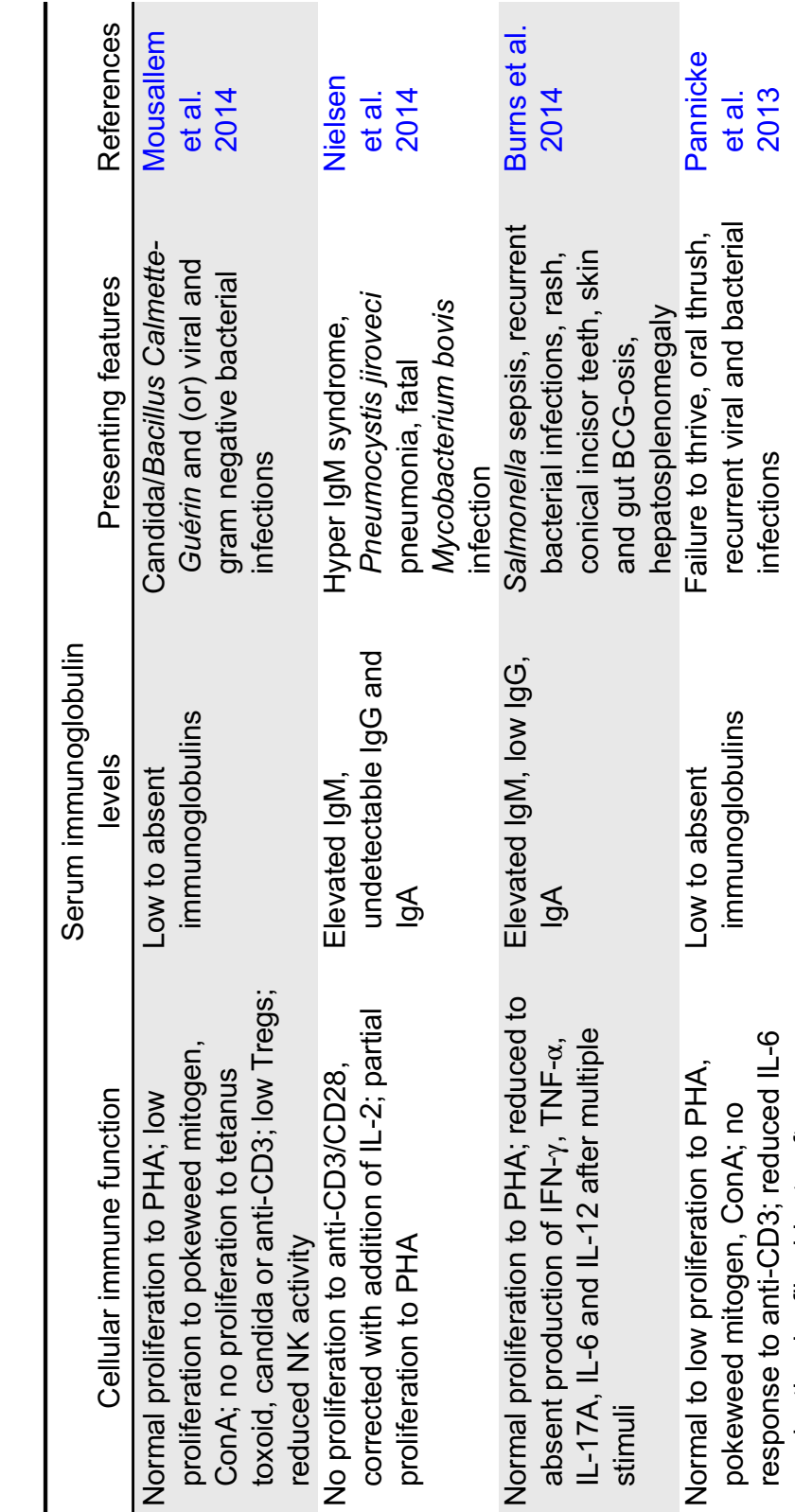

$+$
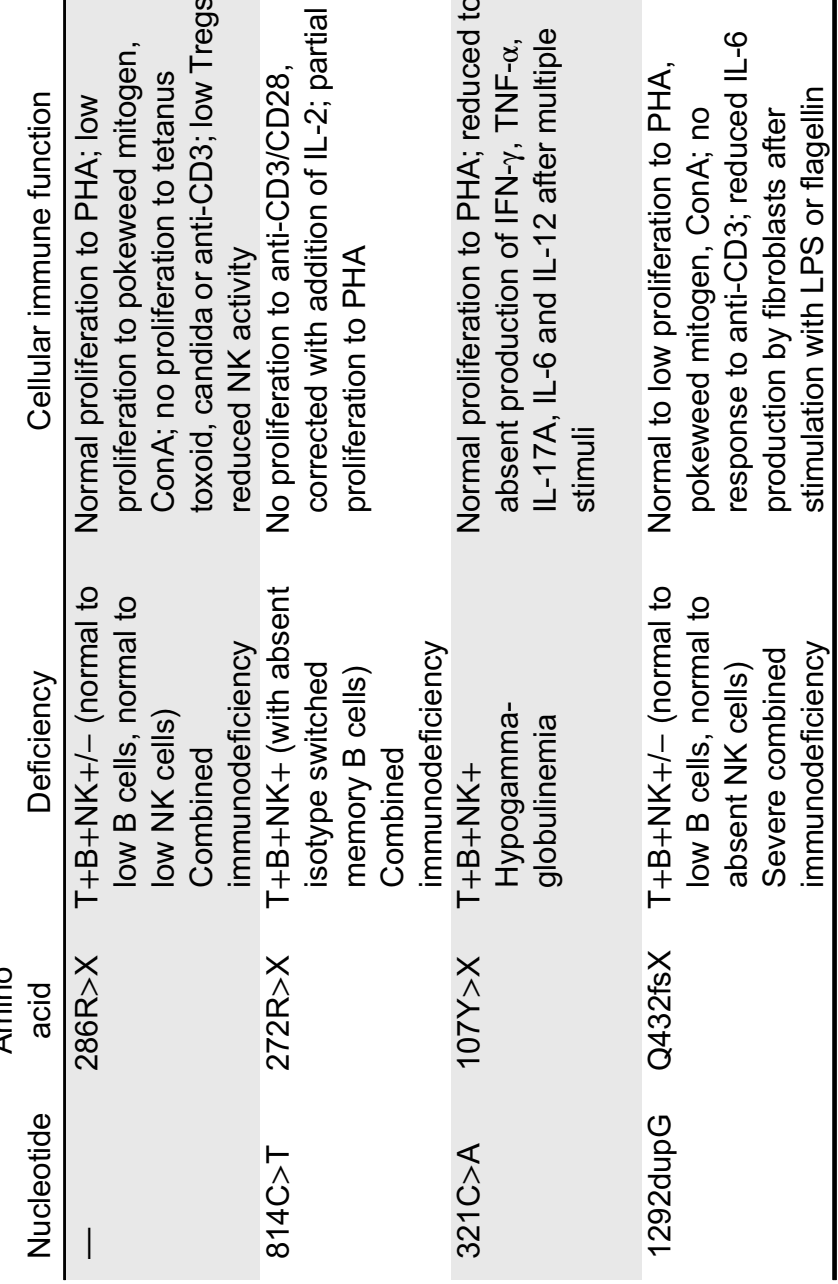

I $\kappa K \alpha$, and IKK $\beta$ and we show a wide clinical spectrum of immunodeficiency and infectious phenotypes. This database can aid the clinician in recognizing specific immunodeficiency phenotypes and promote the diagnosis of NFkB pathway defects.

\section{REFERENCES}

Abinun, M., Spickett, G., Appleton, A.L., Flood, T., and Cant, A.J. 1996. Anhidrotic ectodermal dysplasia associated with specific antibody deficiency. Eur. J. Pediatr. 155(2):146-147. PMID: 8775234. doi: 10.1007/BF02075774.

Aradhya, S., Bardaro, T., Galgoczy, P., Yamagata, T., Esposito, T., Patlan, H., Ciccodicola, A., Munnich, A., Kenwrick, S., Platzer, M., D’Urso, M., and Nelson, D.L. 2001. Multiple pathogenic and benign genomic rearrangements occur at a $35 \mathrm{~kb}$ duplication involving the NEMO and LAGE2 genes. Hum. Mol. Genet. 10(22):2557-2567. PMID: 11709543. doi: 10.1093/ $\mathrm{hmg} / 10.22 .2557$.

Brodeur, S.R., Angelini, F., Bacharier, L.B., Blom, A.M., Mizoguchi, E., Fujiwara, H., Plebani, A., Notarangelo, L.D., Dahlback, B., Tsitsikov, E., and Geha, R.S. 2003. C4b-binding protein (C4BP) activates $\mathrm{B}$ cells through the $\mathrm{CD} 40$ receptor. Immunity. 18(6):837-848. PMID: 12818164. doi: 10.1016/ S1074-7613(03)00149-3.

Burns, S.O., Plagnol, V., Gutierrez, B.M., Al Zahrani, D., Curtis, J., Gaspar, M., Hassan, A., Jones, A.M., Malone, M., Rampling, D., McLatchie, A., Doffinger, R., Gilmour, K.C., Henriquez, F., Thrasher, A.J., Gaspar, H.B., and Nejentsev, S. 2014. Immunodeficiency and disseminated mycobacterial infection associated with homozygous nonsense mutation of IKK $\beta$. J. Allergy Clin. Immunol. 134(1):215-218. PMID: 24679846. doi: 10.1016/j. jaci.2013.12.1093.

Carrol, E.D., Gennery, A.R., Flood, T.J., Spickett, G.P., and Abinun, M. 2003. Anhidrotic ectodermal dysplasia and immunodeficiency: The role of NEMO. Arch. Dis. Child. 88(4):340-341. PMID: 12651765.

Courtois, G., and Gilmore, T.D. 2006. Mutations in the NF-kappaB signaling pathway: Implications for human disease. Oncogene. 25(51):6831-6843. PMID: 17072331. doi: 10.1038/sj.onc.1209939.

Courtois, G., Smahi, A., Reichenbach, J., Doffinger, R., Cancrini, C., Bonnet, M., Puel, A., Chable-Bessia, C., Yamaoka, S., Feinberg, J., Dupuis-Girod, S., Bodemer, C., Livadiotti, S., Novelli, F., Rossi, P., Fischer, A., Israel, A., Munnich, A., Le Deist, F., and Casanova, J.L. 2003. A hypermorphic IkappaBalpha 
mutation is associated with autosomal dominant anhidrotic ectodermal dysplasia and T cell immunodeficiency. J. Clin. Invest. 112(7):1108-1115. PMID: 14523047. doi: 10.1172/JCI18714.

Dai, Y.S., Liang, M.G., Gellis, S.E., Bonilla, F.A., Schneider, L.C., Geha, R.S., and Orange, J.S. 2004. Characteristics of mycobacterial infection in patients with immunodeficiency and nuclear factor-kappaB essential modulator mutation, with or without ectodermal dysplasia. J. Am. Acad. Dermatol. 51(5):718-722. PMID: 15523349. doi: 10.1016/j.jaad.2004.05.032.

Deering, R.P., and Orange, J.S. 2006. Development of a clinical assay to evaluate toll-like receptor function. Clin. Vaccine Immunol. 13(1):68-76. PMID: 16426002. doi: 10.1128/CVI.13.1.68-76.2006.

Devora, G.A., Sun, L., Chen, Z., van Oers, N.S., Hanson, E.P., Orange, J.S., and de la Morena, M.T. 2010. A novel missense mutation in the nuclear factor-kappaB essential modulator (NEMO) gene resulting in impaired activation of the NF-kappaB pathway and a unique clinical phenotype presenting as MRSA subdural empyema. J. Clin. Immunol. 30(6):881-885. PMID: 20652730. doi: 10.1007/s10875-010-9445-y.

Doffinger, R., Smahi, A., Bessia, C., Geissmann, F., Feinberg, J., Durandy, A., Bodemer, C., Kenwrick, S., Dupuis-Girod, S., Blanche, S., Wood, P., Rabia, S.H., Headon, D.J., Overbeek, P.A., Le Deist, F., Holland, S.M., Belani, K., Kumararatne, D.S., Fischer, A., Shapiro, R., Conley, M.E., Reimund, E., Kalhoff, H., Abinun, M., Munnich, A., Israel, A., Courtois, G., and Casanova, J.L. 2001. X-linked anhidrotic ectodermal dysplasia with immunodeficiency is caused by impaired NF-kappaB signaling. Nat. Genet. 27(3):277-285. PMID: 11242109. doi: $10.1038 / 85837$.

Dupuis-Girod, S., Corradini, N., Hadj-Rabia, S., Fournet, J.C., Faivre, L., Le Deist, F., Durand, P., Doffinger, R., Smahi, A., Israel, A., Courtois, G., Brousse, N., Blanche, S., Munnich, A., Fischer, A., Casanova, J.L., and Bodemer, C. 2002. Osteopetrosis, lymphedema, anhidrotic ectodermal dysplasia, and immunodeficiency in a boy and incontinentia pigmenti in his mother. Pediatrics. 109(6):e97. PMID: 12042591.

Filipe-Santos, O., Bustamante, J., Haverkamp, M.H., Vinolo, E., Ku, C.L., Puel, A., Frucht, D.M., Christel, K., von Bernuth, H., Jouanguy, E., Feinberg, J., Durandy, A., Senechal, B., Chapgier, A., Vogt, G., de Beaucoudrey, L., Fieschi, C., Picard, C., Garfa, M., Chemli, J., Bejaoui, M., Tsolia, M.N., Kutukculer, N., Plebani, A., Notarangelo, L., Bodemer, C., Geissmann, F., Israel, A., Veron, M., Knackstedt, M.,
Barbouche, R., Abel, L., Magdorf, K., Gendrel, D., Agou, F., Holland, S.M., and Casanova, J.L. 2006. X-linked susceptibility to mycobacteria is caused by mutations in NEMO impairing CD40-dependent IL-12 production. J. Exp. Med. 203(7):1745-1759. PMID: 16818673. doi: 10.1084/jem.20060085.

Gilmore, T.D. 2006. Introduction to NF-kappaB: Players, pathways, perspectives. Oncogene. 25(51):6680-6684. PMID: 17072321. doi: 10.1038/sj.onc.1209954.

Hanson, E.P., Monaco-Shawver, L., Solt, L.A., Madge, L.A., Banerjee, P.P., May, M.J., and Orange, J.S. 2008. Hypomorphic nuclear factor-kappaB essential modulator mutation database and reconstitution system identifies phenotypic and immunologic diversity. J. Allergy Clin. Immunol. 122(6):1169-1177.e16. PMID: 18851874. doi: 10.1016/j.jaci.2008.08.018.

Haverkamp, M.H., Arend, S.M., Lindeboom, J.A., Hartwig, N.G., and van Dissel, J.T. 2004. Nontuberculous mycobacterial infection in children: A 2-year prospective surveillance study in the Netherlands. Clin. Infect. Dis. 39(4):450-456. PMID: 15356803. doi: $10.1086 / 422319$.

Holland, S.M., Eisenstein, E.M., Kuhns, D.B., Turner, M.L., Fleisher, T.A., Strober, W., and Gallin, J.I. 1994. Treatment of refractory disseminated nontuberculous mycobacterial infection with interferon gamma. A preliminary report. N. Engl. J. Med. 330(19):1348-1355. PMID: 7908719. doi: 10.1056/ NEJM199405123301904.

Hubeau, M., Ngadjeua, F., Puel, A., Israel, L., Feinberg, J., Chrabieh, M., Belani, K., Bodemer, C., Fabre, I., Plebani, A., Boisson-Dupuis, S., Picard, C., Fischer, A., Israel, A., Abel, L., Veron, M., Casanova, J.L., Agou, F., and Bustamante, J. 2011. New mechanism of X-linked anhidrotic ectodermal dysplasia with immunodeficiency: Impairment of ubiquitin binding despite normal folding of NEMO protein. Blood. 118(4):926-935. PMID: 21622647. doi: 10.1182/ blood-2010-10-315234.

Imamura, M., Kawai, T., Okada, S., Izawa, K., Takachi, T., Iwabuchi, H., Yoshida, S., Hosokai, R., Kanegane, H., Yamamoto, T., Umezu, H., Nishikomori, R., Heike, T., Uchiyama, M., and Imai, C. 2011. Disseminated BCG infection mimicking metastatic nasopharyngeal carcinoma in an immunodeficient child with a novel hypomorphic NEMO mutation. J. Clin. Immunol. 31(5):802-810. PMID: 21755389. doi: 10.1007/ s10875-011-9568-9.

Jain, A., Ma, C.A., Liu, S., Brown, M., Cohen, J., and Strober, W. 2001. Specific missense mutations in NEMO result in hyper-IgM syndrome with 
hypohydrotic ectodermal dysplasia. Nat. Immunol. 2(3):223-228. PMID: 11224521. doi: 10.1038/85277.

Janssen, R., van Wengen, A., Hoeve, M.A., ten Dam, M., van der Burg, M., van Dongen, J., van de Vosse, E., van Tol, M., Bredius, R., Ottenhoff, T.H., Weemaes, C., van Dissel, J.T., and Lankester, A. 2004. The same IkappaBalpha mutation in two related individuals leads to completely different clinical syndromes. J. Exp. Med. 200(5):559-568. PMID: 15337789. doi: 10.1084/ jem.20040773.

Karakawa, S., Okada, S., Tsumura, M., Mizoguchi, Y., Ohno, N., Yasunaga, S., Ohtsubo, M., Kawai, T., Nishikomori, R., Sakaguchi, T., Takihara, Y., and Kobayashi, M. 2011. Decreased expression in nuclear factor-kappaB essential modulator due to a novel splice-site mutation causes X-linked ectodermal dysplasia with immunodeficiency. J. Clin. Immunol. 31(5):762-772. PMID: 21720903. doi: 10.1007/ s10875-011-9560-4.

Karamchandani-Patel, G., Hanson, E.P., Saltzman, R., Kimball, C.E., Sorensen, R.U., and Orange, J.S. 2011. Congenital alterations of NEMO glutamic acid 223 result in hypohidrotic ectodermal dysplasia and immunodeficiency with normal serum IgG levels. Ann. Allergy Asthma Immunol. 107(1):50-56. PMID: 21704885. doi: 10.1016/j.anai.2011.03.009.

Kosaki, K., Shimasaki, N., Fukushima, H., Hara, M., Ogata, T., and Matsuo, N. 2001. Female patient showing hypohidrotic ectodermal dysplasia and immunodeficiency (HED-ID). Am. J. Hum. Genet. 69(3):664-665. PMID: 11484156. doi: 10.1086/ 323003.

Ku, C.L., Dupuis-Girod, S., Dittrich, A.M., Bustamante, J., Santos, O.F., Schulze, I., Bertrand, Y., Couly, G., Bodemer, C., Bossuyt, X., Picard, C., and Casanova, J.L. 2005. NEMO mutations in 2 unrelated boys with severe infections and conical teeth. Pediatrics. 115(5):e615-e619. PMID: 15833888. doi: 10.1542/ peds.2004-1754.

Ku, C.L., Picard, C., Erdos, M., Jeurissen, A., Bustamante, J., Puel, A., von Bernuth, H., FilipeSantos, O., Chang, H.H., Lawrence, T., Raes, M., Marodi, L., Bossuyt, X., and Casanova, J.L. 2007. IRAK4 and NEMO mutations in otherwise healthy children with recurrent invasive pneumococcal disease. J. Med. Genet. 44(1):16-23. PMID: 16950813. doi: 10.1136/jmg.2006.044446.

Lee, W.I., Torgerson, T.R., Schumacher, M.J., Yel, L., Zhu, Q., and Ochs, H.D. 2005. Molecular analysis of a large cohort of patients with the hyper immunoglobulin M (IgM) syndrome. Blood.
105(5):1881-1890. PMID: 15358621. doi: 10.1182/ blood-2003-12-4420.

Lopez-Granados, E., Keenan, J.E., Kinney, M.C., Leo, H., Jain, N., Ma, C.A., Quinones, R., Gelfand, E.W., and Jain, A. 2008. A novel mutation in NFKBIA/IKBA results in a degradation-resistant $\mathrm{N}$-truncated protein and is associated with ectodermal dysplasia with immunodeficiency. Hum. Mutat. 29(6):861-868. PMID: 18412279. doi: 10.1002/humu.20740.

Mancini, A.J., Lawley, L.P., and Uzel, G. 2008. X-linked ectodermal dysplasia with immunodeficiency caused by NEMO mutation: Early recognition and diagnosis. Arch. Dermatol. 144(3):342-346. PMID: 18347290. doi: 10.1001/archderm.144.3.342.

Mansour, S., Woffendin, H., Mitton, S., Jeffery, I., Jakins, T., Kenwrick, S., and Murday, V.A. 2001. Incontinentia pigmenti in a surviving male is accompanied by hypohidrotic ectodermal dysplasia and recurrent infection. Am. J. Med. Genet. 99(2):172177. PMID: 11241484.

Martinez-Pomar, N., Munoz-Saa, I., Heine-Suner, D., Martin, A., Smahi, A., and Matamoros, N. 2005. A new mutation in exon 7 of NEMO gene: Late skewed $\mathrm{X}$-chromosome inactivation in an incontinentia pigmenti female patient with immunodeficiency. Hum. Genet. 118(3-4):458-465. PMID: 16228229. doi: 10.1007/s00439-005-0068-y.

McDonald, D.R., Mooster, J.L., Reddy, M., Bawle, E., Secord, E., and Geha, R.S. 2007. Heterozygous $\mathrm{N}$-terminal deletion of IkappaBalpha results in functional nuclear factor kappaB haploinsufficiency, ectodermal dysplasia, and immune deficiency. J. Allergy Clin. Immunol. 120(4):900-907. PMID: 17931563. doi: 10.1016/j.jaci.2007.08.035.

Mooster, J.L., Cancrini, C., Simonetti, A., Rossi, P., Di Matteo, G., Romiti, M.L., Di Cesare, S., Notarangelo, L., Geha, R.S., and McDonald, D.R. 2010. Immune deficiency caused by impaired expression of nuclear factor-kappaB essential modifier (NEMO) because of a mutation in the $5^{\prime}$ untranslated region of the NEMO gene. J. Allergy Clin. Immunol. 126(1):127-132.e7. PMID: 20542322. doi: 10.1016/j.jaci.2010.04.026.

Mousallem, T., Yang, J., Urban, T.J., Wang, H., Adeli, M., Parrott, R.E., Roberts, J.L., Goldstein, D.B., Buckley, R.H., and Zhong, X.P. 2014. A nonsense mutation in IKBKB causes combined immunodeficiency. Blood. 124(13):2046-2050. PMID: 25139357. doi: 10.1182/blood-2014-04-571265.

Niehues, T., Reichenbach, J., Neubert, J., Gudowius, S., Puel, A., Horneff, G., Lainka, E., Dirksen, U., 
Schroten, H., Doffinger, R., Casanova, J.L., and Wahn, V. 2004. Nuclear factor kappaB essential modulator-deficient child with immunodeficiency yet without anhidrotic ectodermal dysplasia. J. Allergy Clin. Immunol. 114(6):1456-1462. PMID: 15577852. doi: 10.1016/j.jaci.2004.08.047.

Nielsen, C., Jakobsen, M.A., Larsen, M.J., Muller, A.C., Hansen, S., Lillevang, S.T., Fisker, N., and Barington, T. 2014. Immunodeficiency associated with a nonsense mutation of IKBKB. J. Clin. Immunol. 34(8):916-921. PMID: 25216719. doi: 10.1007/s10875-014-0097-1.

Nishikomori, R., Akutagawa, H., Maruyama, K., Nakata-Hizume, M., Ohmori, K., Mizuno, K., Yachie, A., Yasumi, T., Kusunoki, T., Heike, T., and Nakahata, T. 2004. X-linked ectodermal dysplasia and immunodeficiency caused by reversion mosaicism of NEMO reveals a critical role for NEMO in human T-cell development and/or survival. Blood. 103(12):4565-4572. PMID: 14726382. doi: 10.1182/ blood-2003-10-3655.

Ohnishi, H., Miyata, R., Suzuki, T., Nose, T., Kubota, K., Kato, Z., Kaneko, H., and Kondo, N. 2012. A rapid screening method to detect autosomal-dominant ectodermal dysplasia with immune deficiency syndrome. J. Allergy Clin. Immunol. 129(2):578-580. PMID: 22078572. doi: 10.1016/j.jaci.2011.09.042.

Orange, J.S., Brodeur, S.R., Jain, A., Bonilla, F.A., Schneider, L.C., Kretschmer, R., Nurko, S., Rasmussen, W.L., Kohler, J.R., Gellis, S.E., Ferguson, B.M., Strominger, J.L., Zonana, J., Ramesh, N., Ballas, Z.K., and Geha, R.S. 2002. Deficient natural killer cell cytotoxicity in patients with IKK-gamma/NEMO mutations. J. Clin. Invest. 109(11):1501-1509. PMID: 12045264. doi: 10.1172/ JCI0214858.

Orange, J.S., Jain, A., Ballas, Z.K., Schneider, L.C., Geha, R.S., and Bonilla, F.A. 2004a. The presentation and natural history of immunodeficiency caused by nuclear factor kappaB essential modulator mutation. J. Allergy Clin. Immunol. 113(4):725-733. PMID: 15100680. doi: 10.1016/j.jaci.2004.01.762.

Orange, J.S., Levy, O., Brodeur, S.R., Krzewski, K., Roy, R.M., Niemela, J.E., Fleisher, T.A., Bonilla, F.A., and Geha, R.S. 2004b. Human nuclear factor kappa B essential modulator mutation can result in immunodeficiency without ectodermal dysplasia. J. Allergy Clin. Immunol. 114(3):650-656. PMID: 15356572. doi: 10.1016/j.jaci.2004.06.052.

Orange, J.S., Levy, O., and Geha, R.S. 2005. Human disease resulting from gene mutations that interfere with appropriate nuclear factor-kappaB activation.
Immunol. Rev. 203:21-37. PMID: 15661019. doi: 10.1111/j.0105-2896.2005.00221.x.

Orstavik, K.H., Kristiansen, M., Knudsen, G.P., Storhaug, K., Vege, A., Eiklid, K., Abrahamsen, T.G., Smahi, A., and Steen-Johnsen, J. 2006. Novel splicing mutation in the NEMO (IKK-gamma) gene with severe immunodeficiency and heterogeneity of X-chromosome inactivation. Am. J. Med. Genet. A. 140(1):31-39. PMID: 16333836. doi: 10.1002/ajmg. a.31026.

Pannicke, U., Baumann, B., Fuchs, S., Henneke, P., Rensing-Ehl, A., Rizzi, M., Janda, A., Hese, K., Schlesier, M., Holzmann, K., Borte, S., Laux, C., Rump, E.M., Rosenberg, A., Zelinski, T., Schrezenmeier, H., Wirth, T., Ehl, S., Schroeder, M.L., and Schwarz, K. 2013. Deficiency of innate and acquired immunity caused by an IKBKB mutation. N. Engl. J. Med. 369(26):2504-2514. PMID: 24369075. doi: 10.1056/NEJMoa1309199.

Puel, A., Reichenbach, J., Bustamante, J., Ku, C.L., Feinberg, J., Doffinger, R., Bonnet, M., FilipeSantos, O., de Beaucoudrey, L., Durandy, A., Horneff, G., Novelli, F., Wahn, V., Smahi, A., Israel, A., Niehues, T., and Casanova, J.L. 2006. The NEMO mutation creating the most-upstream premature stop codon is hypomorphic because of a reinitiation of translation. Am. J. Hum. Genet. 78(4):691-701. PMID: 16532398. doi: 10.1086/501532.

Roberts, C.M., Angus, J.E., Leach, I.H., McDermott, E.M., Walker, D.A., and Ravenscroft, J.C. 2010. A novel NEMO gene mutation causing osteopetrosis, lymphoedema, hypohidrotic ectodermal dysplasia and immunodeficiency (OL-HED-ID). Eur. J. Pediatr. 169(11):1403-1407. PMID: 20499091. doi: 10.1007/ s00431-010-1206-7.

Salt, B.H., Niemela, J.E., Pandey, R., Hanson, E.P., Deering, R.P., Quinones, R., Jain, A., Orange, J.S., and Gelfand, E.W. 2008. IKBKG (nuclear factorkappa $B$ essential modulator) mutation can be associated with opportunistic infection without impairing Toll-like receptor function. J. Allergy Clin. Immunol. 121(4):976-982. PMID: 18179816. doi: 10.1016/j. jaci.2007.11.014.

Schimke, L.F., Rieber, N., Rylaarsdam, S., CabralMarques, O., Hubbard, N., Puel, A., Kallmann, L., Sombke, S.A., Notheis, G., Schwarz, H.P., Kammer, B., Hokfelt, T., Repp, R., Picard, C., Casanova, J.L., Belohradsky, B.H., Albert, M.H., Ochs, H.D., Renner, E.D., and Torgerson, T.R. 2013. A novel gainof-function IKBA mutation underlies ectodermal dysplasia with immunodeficiency and polyendocrinopathy. 
J. Clin. Immunol. 33(6):1088-1099. PMID: 23708964. doi: 10.1007/s10875-013-9906-1.

Schweizer, P., Kalhoff, H., Horneff, G., Wahn, V., and Diekmann, L. 1999. [Polysaccharide specific humoral immunodeficiency in ectodermal dysplasia. Case report of a boy with two affected brothers]. Klin. Padiatr. 211(6):459-461. PMID: 10592927. doi: 10.1055/s-2008-1043834.

Vinolo, E., Sebban, H., Chaffotte, A., Israel, A., Courtois, G., Veron, M., and Agou, F. 2006. A point mutation in NEMO associated with anhidrotic ectodermal dysplasia with immunodeficiency pathology results in destabilization of the oligomer and reduces lipopolysaccharide- and tumor necrosis factormediated NF-kappa B activation. J. Biol. Chem. 281(10):6334-6348. PMID: 16379012. doi: 10.1074/ jbc.M510118200.

von Bernuth, H., Ku, C.L., Rodriguez-Gallego, C., Zhang, S., Garty, B.Z., Marodi, L., Chapel, H.,
Chrabieh, M., Miller, R.L., Picard, C., Puel, A., and Casanova, J.L. 2006. A fast procedure for the detection of defects in Toll-like receptor signaling. Pediatrics. 118(6):2498-2503. PMID: 17142536. doi: 10.1542/peds.2006-1845.

von Bernuth, H., Puel, A., Ku, C.L., Yang, K., Bustamante, J., Chang, H.H., Picard, C., and Casanova, J.L. 2005. Septicemia without sepsis: Inherited disorders of nuclear factor-kappa B-mediated inflammation. Clin. Infect. Dis. 41(Suppl 7):S436-S439. PMID: 16237643. doi: 10.1086/431994. Zonana, J., Elder, M.E., Schneider, L.C., Orlow, S.J., Moss, C., Golabi, M., Shapira, S.K., Farndon, P.A., Wara, D.W., Emmal, S.A., and Ferguson, B.M. 2000. A novel X-linked disorder of immune deficiency and hypohidrotic ectodermal dysplasia is allelic to incontinentia pigmenti and due to mutations in IKKgamma (NEMO). Am. J. Hum. Genet. 67(6):15551562. PMID: 11047757 . doi: 10.1086/316914. 